\title{
Nghiên cứu sự phân bố tải trọng trong quá trình làm việc của móng bè cọc
}

\section{Nguyễn Ngọc Thắng ${ }^{1}$, Nguyễn Trường Hải ${ }^{2 *}$}

${ }^{1}$ Khoa Kỹ thuật công nghệ, Trường Đại học Tiền Giang

${ }^{2}$ Khoa Kỹ thuật công nghệ, Trường Đại học Kinh tế Công nghiệp Long An

\section{TỪ KHOÁ}

\section{Móng bè cọc}

Phần tử hữu hạn

Plaxis

Đất yếu

\section{KEYWORDS}

\section{Pile raft foundation}

FEM

Plaxis

Soft soil

\section{TÓM TẮT}

Móng bè cọc ngày càng được áp dụng rộng rãi, đặc biệt là cho các tòa nhà cao tầng. Trong móng bè cọc, cọc không được thiết kế để chịu toàn bộ tải trọng mà chỉ để giảm độ lún đến một mức độ cho phép. Bài báo này trình bày nghiên cứu sử dụng kết hợp với phương pháp phần tử hữu hạn để thiết kế móng bè cọc. Kết quả nghiên cức chỉ ra rằng: phương pháp móng bè cọc như là một phương án móng thay thế. Phân tích phần mềm Plaxis 3D để xác định độ lún và hệ số phân bố tải trọng trong móng bè cọc.

ABSTRACT

Nowadays pile raft foundation has more and more popularly applied, especially in a high-rise building. For pile raft foundation, pile designed is not to bear full loading. But it minimizes the level of subsidence on allowance limited. This method can combine with FEM (Finite elements method) to design pile raft foundation. It is also studied such as an alternative proposal for foundation structure. The Plaxis 3D software uses to measure settlement and factor of weight distribution in pile raft foundation.

\section{1. Đặt vấn đề}

Theo một số quan điểm thiết kế móng cọc hiện nay, người ta chưa xem xét đến sự làm việc của đất nền dưới đáy bè mà chỉ xem tải trọng công trình là do cọc chịu $100 \%$, nhưng theo quan điểm móng bè cọc $(\mathrm{MBC})$ thì tải trọng công trình vừa phân phối lên bè và vừa phân phối lên cọc. Vì thế, móng bè cọc đã trở thành giải pháp móng hữu hiệu nhất áp dụng cho các công trình cao tầng ở trên thế giới vì khả năng chịu lực, độ lún của bè và sức chịu tải của cọc được cải thiện đáng kể so với móng cọc thông thường. Sự hiệu quả về kinh tế của móng bè cọc hầu hết được trình bày bởi Randolph (1994) là những chiếc bè và cọc cùng tham gia chịu tải và làm cho độ lún, độ lún lệch giữa bè-cọc vẫn nằm trong phạm vi cho phép.

\section{Phương pháp nghiên cứu}

\subsection{Phương pháp Poulos - Davis - Randolph (PDR)}

Khi thiết kế móng ta cần quan tâm hai giá trị: sức chịu tải và độ lún của móng.

Sức chịu tải cực hạn của móng bè cọc là giá trị nhỏ hơn trong hai giá trị sau:

+ Tổng khả năng chịu tải cực hạn của bè và các cọc.

+ Khả năng chịu tải cực hạn của khối gồm cọc và bè cộng với một phần bè nằm bên ngoài cọc.

Quan hệ giữa tải trọng và độ lún của móng bè cọc được tính toán bằng phương pháp đơn giản của Poulos và Davis (1980). Năm 1994, Randolph đã phát triển phương pháp này để tính toán sự phân bố tải trọng giữa bè và cọc.
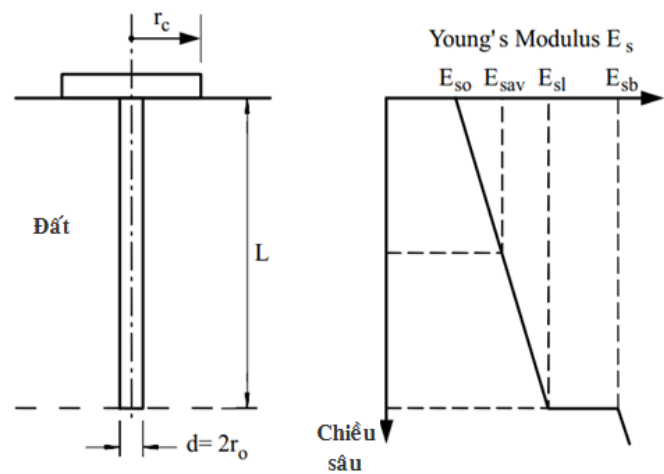

Hình 1. Chuyển vị của nền đất yếu được gia cố.

Theo Randolph, độ cứng của móng bè cọc có thể tính theo công thức sau:

$$
K_{p r}=\frac{K_{p}+K_{r}\left(1-\alpha_{c p}\right)}{1-\alpha_{c p}^{2} K_{r} / K_{p}}
$$

Trong đó: $\mathrm{K}_{\mathrm{pr}}$ : độ cứng của bè cọc, $\mathrm{K}_{\mathrm{p}}$ : độ cứng của nhóm cọc; $\mathrm{K}_{\mathrm{r}}$ : độ cứng của bè; $\alpha_{\mathrm{cp}}$ : hệ số tương tác giữa bè và cọc.

Độ cứng của bè $\mathrm{K}_{\mathrm{r}}$ có thể được tính theo lý thuyết đàn hồi, ví dụ dùng lời giải của Fraser và Wardle (1976) hoặc của Mayne và Poulos (1999). 
Theo Mayne và Poulos (1999) thì:

$$
K_{r} \approx\left(\frac{E_{f d n}}{E_{s A V}}\right)\left(\frac{t}{a}\right)^{3}
$$

Trong đó: a: bán kính móng; $\mathrm{E}_{\mathrm{fdn}}$ : module đàn hồi của vật liệu móng (như bê tông cốt thép); $\mathrm{E}_{\mathrm{sAv}}$ : module đàn hồi của đất bên dưới móng; t: chiều dày móng.

Độ cứng của nhóm cọc $\mathrm{K}_{\mathrm{p}}$ cũng được tính theo lý thuyết đàn hồi như quan điểm của Poulos và Davis (1980), Fleming và các cộng sự (1992) hoặc Poulos (1989). Trong trường hợp đơn giản, độ cứng của cọc đơn được tính dựa vào giả thiết đàn hồi rồi nhân thêm hệ số độ cứng nhóm. với e nằm trong khoảng từ 0,3 đến 0,5 .

Đối với cọc ma sát, Fleming và các cộng sự (1992) đưa ra các biểu đồ để xác định giá trị e:

$$
e=e_{1} \cdot(l / d) \cdot c_{1} \cdot\left(E_{p} / G\right) \cdot c_{2} \cdot(s / d) \cdot c_{3}(\rho) \cdot c_{4}(v)
$$

Tỉ số tải trọng được gánh đỡ bởi phần bè gọi là $\alpha_{\mathrm{PR}}$ được tính dựa theo công thức sau:

$$
\frac{P_{r}}{P_{t}}=\frac{K_{r}\left(1-\alpha_{c p}\right)}{K_{p}+K_{r}\left(1-\alpha_{c p}\right)}=\alpha_{P R}
$$

Trong đó: $\mathrm{P}_{\mathrm{r}}$ : tải trọng được gánh đỡ bởi bè; $\mathrm{P}_{\mathrm{t}}$ : tổng tải trọng tác dụng lên bè cọc.

Hệ số tương tác giữa bè và cọc $\alpha_{\mathrm{cp}}$ có thể tính theo công thức sau:

$$
\alpha_{c p}=1-\frac{\ln \left(\frac{r_{c}}{r_{o}}\right)}{\zeta}
$$

Trong đó: $\mathrm{r}_{\mathrm{c}}$ : bán kính trung bình của bè; $\mathrm{r}_{0}$ : bán kính của cọc; $v$ : hệ số poissons của đất; $\mathrm{L}$ : chiều dài cọc; $\mathrm{E}_{\mathrm{s}}$ : module Young của đất tại độ sâu đầu mũi cọc; $\mathrm{E}_{\mathrm{sb}}$ : module Young của đất bên dưới mũi cọc; $\mathrm{E}_{\mathrm{asv}}$ : module Young trung bình dọc thân cọc.

\subsection{Phương pháp phần tử hữu hạn}

Phương pháp phần tử hữu hạn là một trong các phương pháp mạnh nhất để phân tích móng bè cọc. Trong phương pháp này, cả kết cấu gồm bè cọc và nền đều được rời rạc hóa. Khi đó số lượng phương trình cân bằng sẽ rất lớn, chỉ có thể tính toán dựa vào máy tính.

\section{Phân tích các yếu tố ảnh hưởng trong móng bè cọc}

\subsection{Xây dựng mô hình nghiên cứu}

Xây dựng mô hình phân tích là một hệ móng bè cọc đơn giản, kích thước phần bè không đổi $11 \mathrm{~m} \mathrm{x} 11 \mathrm{~m}$, chịu tải trọng phân bố đều $\mathrm{q}=400 \mathrm{kPa}$ như chính tải trọng phân bố của công trình (Hình 2 và Hình 3). Bằng cách lần lượt thay đổi các thông số cho bè, cho cọc và cho đất nền, ta sẽ phân tích các ảnh hưởng tiêu biểu đến ứng xử của móng bè, đặc biệt là quan tâm đến thông số độ lún và hệ số phân phối Bảng 1. tải trọng $\alpha_{\mathrm{PR}}$.

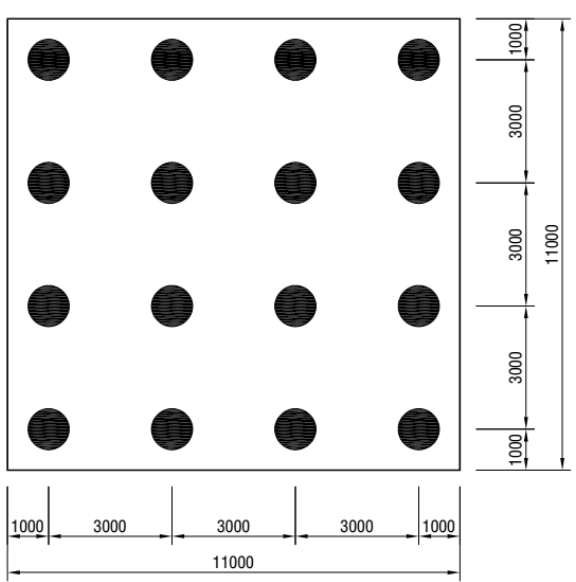

Hình 2. Mặt bằng móng bè cọc.

Bè được thiết kế là bản phẳng để đơn giản cho việc nghiên cứu và so sánh. Chiều dày bè thay đổi từ $0,5 \mathrm{~m}-2,0 \mathrm{~m}$ nhằm mục đích khảo sát vai trò của bè. Bè được mô phỏng như phần tử bản mỏng đặt trên nền móng gồm 16 cọc, bên cạnh đó cũng thay đổi vị trí và số lượng cọc. Trong nghiên cứu này, đề xuất sơ đồ bố trí cọc đều trên bè với phương án chiều dài cọc $\mathrm{L}=30 \mathrm{~m}$ và $\mathrm{L}=40 \mathrm{~m}$ và đường kính cọc $\mathrm{D}=1,0 \mathrm{~m}$. Nhưng tổng sức chịu tải do cọc chịu ở tất cả các cọc đều như nhau.

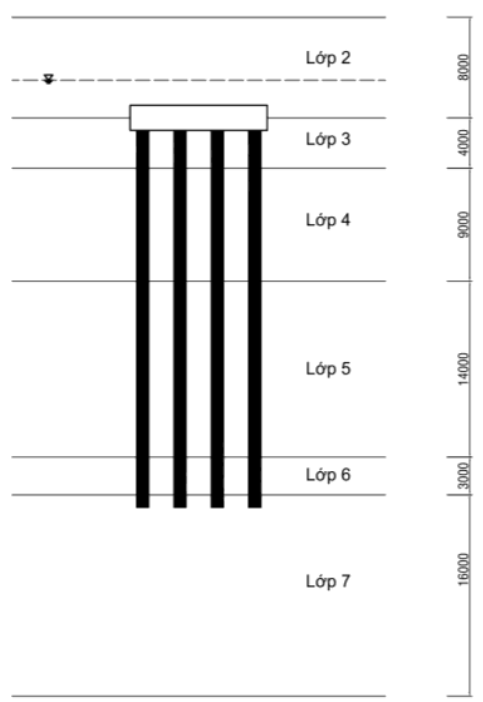

Hình 3. Mặt cắt móng bè cọc.

Các đặc trưng của đất nền sử dụng cho nghiên cứu lấy từ công trình Trung tâm Ung bướu - Bệnh viện Chợ Rẫy, 201B Nguyễn Chí Thanh, phường 12, quận 5, TP. Hồ Chí Minh. Các chỉ tiêu cơ lý chủ yếu của đất được lấy dựa trên hồ sơ khảo sát địa chất. Tóm tắt các thông số đất nền dưới bè móng như Bảng 1 . 
Thông số các lớp đất trong mô hình Plaxis 3D.

\begin{tabular}{|c|c|c|c|c|c|c|c|c|}
\hline STT & Tham số & Ký hiệu & Lớp 2 & Lớp 3 & Lớp 4 & Lớp 5 & Lớp 6 & Lớp 7 \\
\hline 1 & Mô hình & Model & $\begin{array}{l}\text { Mohr - } \\
\text { Coulomb }\end{array}$ & $\begin{array}{c}\text { Mohr - } \\
\text { Coulomb }\end{array}$ & $\begin{array}{l}\text { Mohr - } \\
\text { Coulomb }\end{array}$ & $\begin{array}{c}\text { Mohr - } \\
\text { Coulomb }\end{array}$ & $\begin{array}{c}\text { Mohr - } \\
\text { Coulomb }\end{array}$ & $\begin{array}{c}\text { Mohr - } \\
\text { Coulomb }\end{array}$ \\
\hline 2 & Ứng xử vật liệu & Type & Undrained & Undrained & Drained & Undrained & Drained & Undrained \\
\hline 3 & Dung trọng tự nhiên $\left(\mathrm{kN} / \mathrm{m}^{3}\right)$ & $\gamma_{\text {unsat }}$ & 19,20 & 18,60 & 18,00 & 18,90 & 18,00 & 20,10 \\
\hline 4 & Dung trọng bão hòa $\left(\mathrm{kN} / \mathrm{m}^{3}\right)$ & $\gamma_{\text {sat }}$ & 19,50 & 19,58 & 20,00 & 19,74 & 20,00 & 20,37 \\
\hline 5 & Hệ số thấm phương x (m/day) & $\mathrm{k}_{\mathrm{x}}$ & $10^{-6}$ & $10^{-6}$ & $10^{-3}$ & $10^{-6}$ & $10^{-3}$ & $10^{-6}$ \\
\hline 6 & Hệ số thấm phương y (m/day) & $\mathrm{k}_{\mathrm{y}}$ & $10^{-6}$ & $10^{-6}$ & $10^{-3}$ & $10^{-6}$ & $10^{-3}$ & $10^{-6}$ \\
\hline 7 & Mô đun tổng biến dạng, $\mathrm{E}\left(\mathrm{kN} / \mathrm{m}^{2}\right)$ & E & 11600 & 8180 & 14850 & 9480 & 13980 & 43500 \\
\hline 8 & Hệ số Poisson (-) & $v$ & 0,317 & 0,272 & 0,330 & 0,237 & 0,330 & 0,325 \\
\hline 9 & Cường độ kháng cắt $\left(\mathrm{kN} / \mathrm{m}^{2}\right)$ & c & 23,00 & 4,00 & 10,00 & 6,00 & 10,00 & 46,00 \\
\hline 10 & Góc ma sát trong $\left({ }^{0}\right)$ & $\varphi$ & $16^{\circ} 32^{\prime}$ & $29^{\circ} 44^{\prime}$ & $25^{\circ} 46^{\prime}$ & $30^{\circ} 22^{\prime}$ & $24^{\circ} 30^{\prime}$ & $19^{\circ} 49^{\prime}$ \\
\hline 11 & Góc dãn nở $\left({ }^{0}\right)$ & $\psi$ & $0^{\circ}$ & $0^{\circ}$ & $0^{\circ}$ & $0^{\circ}$ & $0^{\circ}$ & $0^{\circ}$ \\
\hline
\end{tabular}

\section{Bảng 2.}

Thông số móng bè cọc trong mô hình Plaxis 3D.

\begin{tabular}{|c|l|c|c|}
\hline STT & \multicolumn{1}{|c|}{ Tham số } & Ký hiệu & Móng bè cọc \\
\hline 1 & Mô hình & Model & Linear - elastic \\
\hline 2 & Ú́ng xử vật liệu & Type & Non - porous \\
\hline 3 & Dung trọng tự nhiên $\left(\mathrm{kN} / \mathrm{m}^{3}\right)$ & $\gamma_{\text {unsat }}$ & 25 \\
\hline 7 & Mô đun Young, $\mathrm{E}\left(\mathrm{kN} / \mathrm{m}^{2}\right)$ & $\mathrm{E}$ & $30.10^{6}$ \\
\hline 8 & Hệ số Poisson $(-)$ & $v$ & 0,200 \\
\hline
\end{tabular}

Ứng xử của vật liệu: Đất là vật liệu phức tạp gồm 3 thành phần tạo thành: hạt đất, nước và khí. Khi chịu tải trọng ngoài, tải trọng này gần như được gánh đỡ bởi phần nước tạo thành áp lực nước lỗ rỗng thặng dư trong đất. Theo thời gian, áp lực nước lỗ rỗng thặng dư sẽ tiêu tán đồng thời với quá trình này, các hạt đất sẽ gánh đỡ phần áp lực do nước truyền sang. Chính điều này gây ra sự phức tạp trong quá trình tính toán và thiết kế nền. Phần mềm Plaxis chia ra làm 3 loại vật liệu ứng xử:

+ Ứng xử Drained: Đất và nước xem như một vật liệu duy nhất (đất) đang chịu tải, không liên quan gì đến thoát nước, không tạo ra áp lực nước lỗ rỗng thặng dư. Dùng phù hợp cho đất khô, thoát nước hoàn toàn do hệ số thấm cao (đất cát) hay tốc độ gia tải chậm. Mô phỏng ứng xử lâu dài của vật liệu mà không cần quan tâm đến lịch sử cố kết.

+ Ứng xử Undrained: Đất và nước xem như hai vật liệu đang chịu tải, có cả áp lực nước lỗ rỗng ban đầu và áp lực nước lỗ rỗng thặng dư.

+ Ứng xử Non-porous: Sử dụng mô hình này khi áp lực nước lỗ rỗng không vượt quá áp lực trong lớp đó. Ứng xử này có thể thấy trong mô hình kết cấu bê tông và đá. Quan hệ không thoát nước lỗ rỗng thường dung kết hợp với mô hình đàn hồi tuyến tính.

Mô hình nền trong là một tập hợp các phương trình toán học quy định mối quan hệ giữa ứng suất và biến dạng của đất nền khi chịu tác dụng của tải trọng ngoài. Trong nghiên cứu này là sử dụng Mô hình Morh
- Coulomb, mô hình bao gồm các thông số sau: E: Mô đun đàn hồi vật liệu (kN/m²); v: hệ số Poisson; $\varphi$ : góc ma sát trong $\left({ }^{\circ}\right)$; c: lực dính $\left(\mathrm{kN} / \mathrm{m}^{2}\right)$; $\gamma$ : Dung trọng $\left(\mathrm{kN} / \mathrm{m}^{3}\right)$.

Các thông số của cọc và đài móng được trình bày trong Bảng 2 .

\subsection{Phân tích các ảnh hưởng}

Tiến hành khảo sát ảnh hưởng của chiều dài cọc, chiều dày móng, tải trọng ngoài khác nhau đến thông số độ lún và hệ số phân bố tải trọng $\alpha_{\mathrm{PR}}$. Tổng cộng có 24 trường hợp mô phỏng như Bảng 3.

\section{Bảng 3.}

Các trường hợp mô phỏng.

\begin{tabular}{|c|c|c|c|}
\hline $\begin{array}{c}\text { Các trường hợp } \\
\text { mô phỏng }\end{array}$ & $\begin{array}{l}\text { Chiều dài } \\
\text { cọc (m) }\end{array}$ & $\begin{array}{c}\text { Kích thước móng } \\
\text { L x B x H (m) }\end{array}$ & $\begin{array}{c}\text { Tải trọng ngoài } \\
\mathrm{q}, \mathrm{kN} / \mathrm{m}^{2}\end{array}$ \\
\hline Trường hợp 1 & \multirow{12}{*}{30} & \multirow{4}{*}{$11,0 \times 11,0 \times 0,5$} & 100 \\
\hline Trường hợp 2 & & & 200 \\
\hline Trường hợp 3 & & & 300 \\
\hline Trường hợp 4 & & & 400 \\
\hline Trường hợp 5 & & \multirow{4}{*}{$11,0 \times 11,0 \times 1,0$} & 100 \\
\hline Trường hợp 6 & & & 200 \\
\hline Trường hợp 7 & & & 300 \\
\hline Trường hợp 8 & & & 400 \\
\hline Trường hợp 9 & & \multirow{4}{*}{$11,0 \times 11,0 \times 2,0$} & 100 \\
\hline Trường hợp 10 & & & 200 \\
\hline Trường hợp 11 & & & 300 \\
\hline Trường hợp 12 & & & 400 \\
\hline Trường hợp 13 & \multirow{2}{*}{40} & \multirow{2}{*}{$11,0 \times 11,0 \times 0,5$} & 100 \\
\hline Trường hợp 14 & & & 200 \\
\hline
\end{tabular}




\begin{tabular}{|c|c|c|c|}
\hline $\begin{array}{c}\text { Các trường hợp } \\
\text { mô phỏng }\end{array}$ & $\begin{array}{l}\text { Chiều dài } \\
\text { cọc (m) }\end{array}$ & $\begin{array}{c}\text { Kích thước móng } \\
\text { L x B x H (m) }\end{array}$ & $\begin{array}{c}\text { Tải trọng ngoài } \\
\mathrm{q}, \mathrm{kN} / \mathrm{m}^{2}\end{array}$ \\
\hline Trường hợp 15 & & & 300 \\
\hline Trường hợp 16 & & & 400 \\
\hline Trường hợp 17 & & \multirow{4}{*}{$11,0 \times 11,0 \times 1,0$} & 100 \\
\hline Trường hợp 18 & & & 200 \\
\hline Trường hợp 19 & & & 300 \\
\hline Trường hợp 20 & & & 400 \\
\hline Trường hợp 21 & & \multirow{4}{*}{$11,0 \times 11,0 \times 2,0$} & 100 \\
\hline Trường hợp 22 & & & 200 \\
\hline Trường hợp 23 & & & 300 \\
\hline Trường hợp 24 & & & 400 \\
\hline
\end{tabular}

\subsection{Quá trình mô phỏng}

Nghiên cứu phân tích các mô hình bài toán bằng phương pháp phần tử hữu hạn 3D (Plaxis 3D Foundation), phương pháp này giúp làm rõ được ảnh hưởng của từng thông số địa chất đến ứng xử lún cũng như việc phân phối tải trọng cho cọc và đất nền. Giúp người kỹ sư thiết kế có cái nhìn tổng quát và lựa chọn giải pháp móng bè cọc là khả thi hay không. Quá trình mô phỏng số bằng phần mềm Plaxis $3 \mathrm{D}$ Foundation được trình bày từ Hình 4 đến Hình 8.

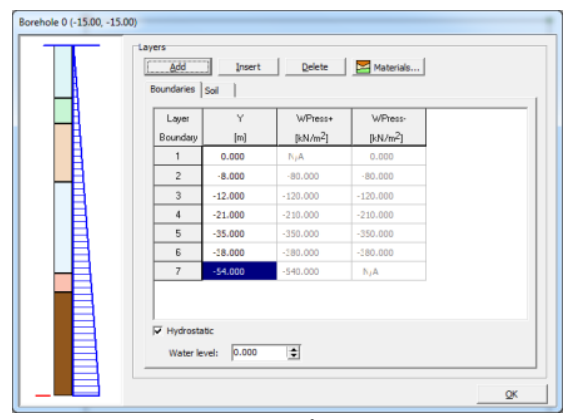

Hình 4. Cửa sổ lỗ khoan.

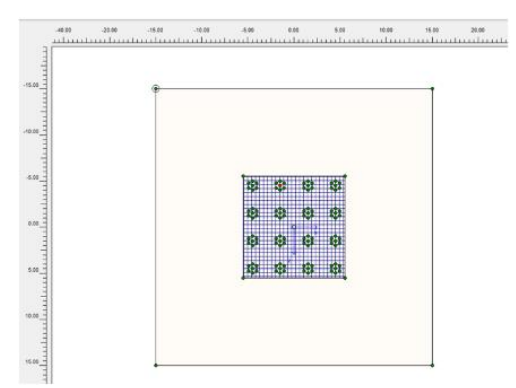

Hình 5. Mặt bằng bố trí cọc.

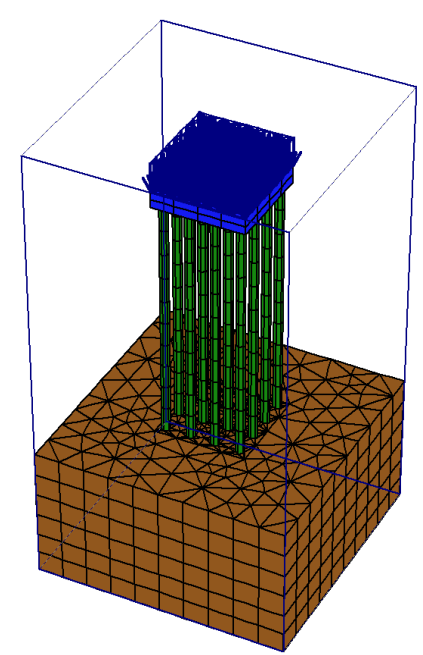

Hình 6. Mô hình PTHH trong Plaxis 3D Foundation.

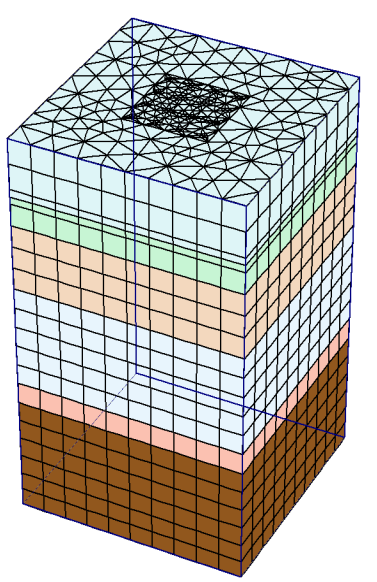

Hình 7. Lưới PTHH của các lớp đất.

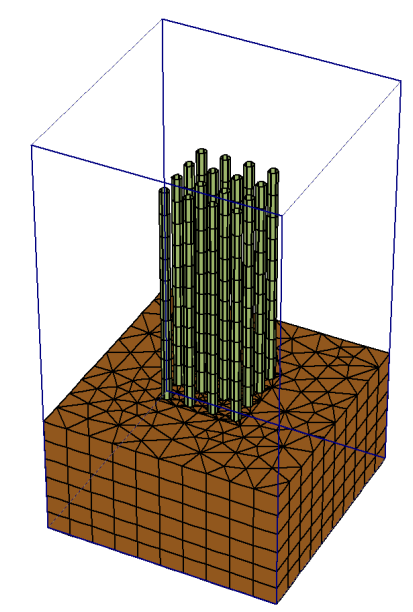

Hình 8. Lưới PTHH của cọc BTCT. 
Kết quả mô phỏng chuyển vị của móng bè cọc thể hiện tại Hình 9, ứng suất trong móng bè cọc tại Hình 10, ứng suất tại đầu cọc tại Hình 11 và ứng suất trong bè tại Hình 12 .
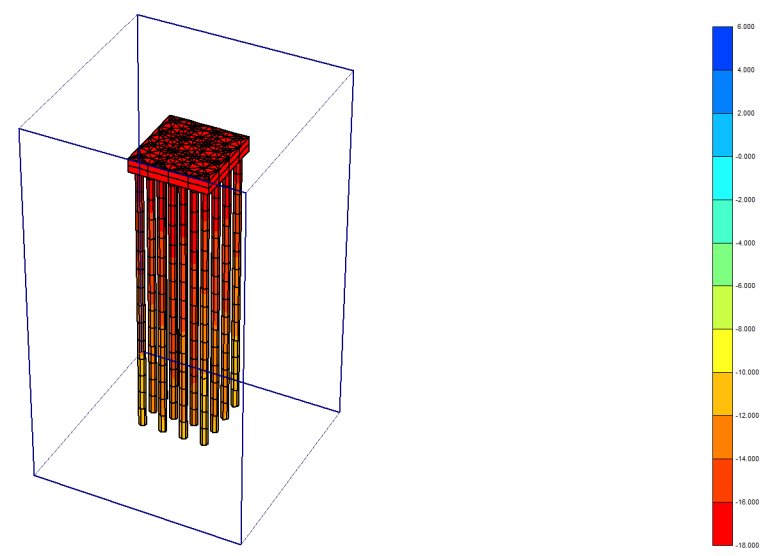

Hình 9. Chuyển vị theo phương đứng trong MBC.

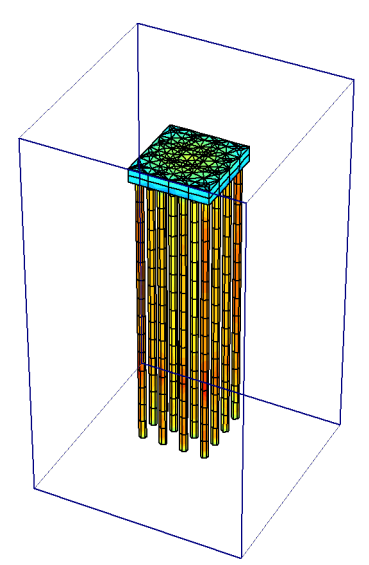

Hình 10. Ứng suất trong MBC.

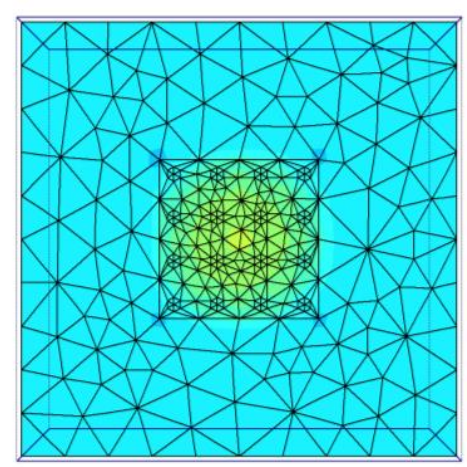

Hình 11. Ứng suất tại đầu cọc.
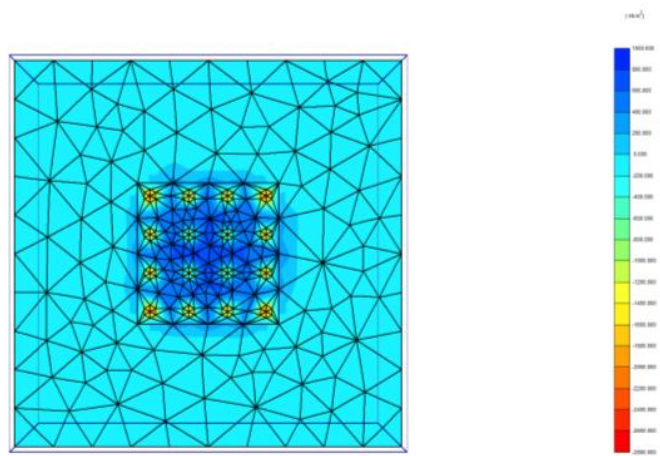

Hình 12. Ứng suất trong móng bè.

\section{Kết quả tính toán}

Với chiều dài cọc $\mathrm{L}=30 \mathrm{~m}$, khi áp lực do tải trọng ngoài tăng từ $100 \mathrm{kPa}$ đến $400 \mathrm{kPa}$ thì độ lún tăng theo chiều dày bè móng $0,5 \mathrm{~m}$ từ $10,02 \mathrm{~mm}$ đến $37,36 \mathrm{~mm}$, trong khi đó độ lún lệch giảm dần theo chiều dày bè móng $1,0 \mathrm{~m}$ từ $9,21 \mathrm{~mm}$ đến $33,73 \mathrm{~mm}$, chiều dày bè móng $2,0 \mathrm{~m}$ từ 8,97 mm đến 31,89 mm (Hình 13).

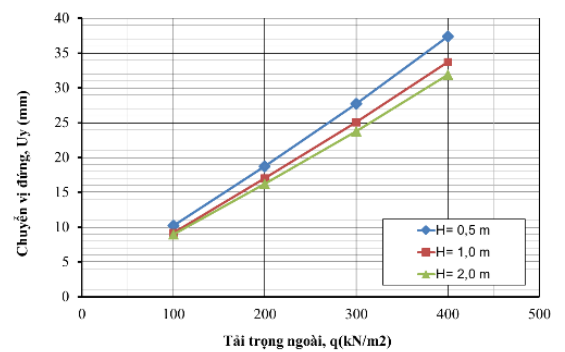

Hình 13. Ảnh hưởng của tải trọng ngoài đến chuyển vị theo phương đứng khi móng có chiều dày bè thay đổi, $\mathrm{L}=30 \mathrm{~m}$.

Với chiều dài cọc $\mathrm{L}=40 \mathrm{~m}$, khi áp lực do tải trọng ngoài tăng từ $100 \mathrm{kPa}$ đến $400 \mathrm{kPa}$ thì độ lún tăng theo chiều dày bè móng $0,5 \mathrm{~m}$ từ $6,05 \mathrm{~mm}$ đến $21,51 \mathrm{~mm}$, trong khi đó độ lún lệch giảm dần theo chiều dày bè móng $1,0 \mathrm{~m}$ từ $5,53 \mathrm{~mm}$ đến $19,17 \mathrm{~mm}$, chiều dày bè móng 2,0 $m$ từ 5,29 mm đến 17,71 mm (Hình 14).

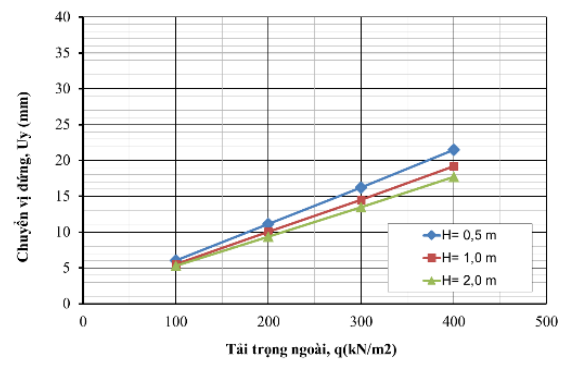

Hình 14. Ảnh hưởng của tải trọng ngoài đến chuyển vị theo phương đứng khi móng có chiều dày bè thay đổi, $\mathrm{L}=40 \mathrm{~m}$. 
Độ lún tối đa móng bè cọc không bị ảnh hưởng bởi việc thay đổi chiều dày bè, độ lún dao động trong khoảng từ 31,89 mm đến 37,36 mm khi cọc có chiều dài $\mathrm{L}=30 \mathrm{~m}$ (Hình 15 ) và từ $17,71 \mathrm{~mm}$ đến $21,51 \mathrm{~mm}$ khi cọc có chiều dài $\mathrm{L}=40 \mathrm{~m}$ (Hình 16 ). Độ lún lệch giữa tâm bè và cạnh bè bị ảnh hưởng rất lớn do sự thay đổi chiều dày bè, và khi đạt đến một chiều dày ổn định thì độ lún lệch không còn nữa.

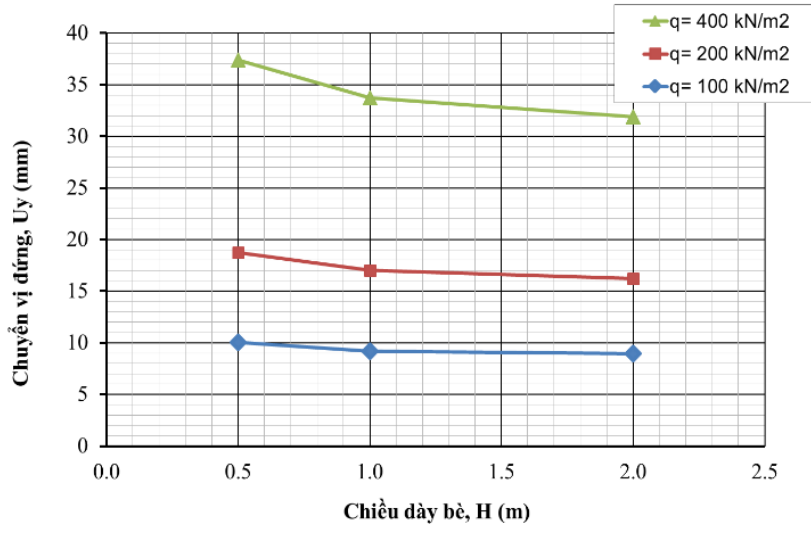

Hình 15. Ảnh hưởng của chiều dày bè đến chuyển vị theo phương đứng khi móng chịu tải trọng ngoài thay đổi, $\mathrm{L}=30 \mathrm{~m}$.

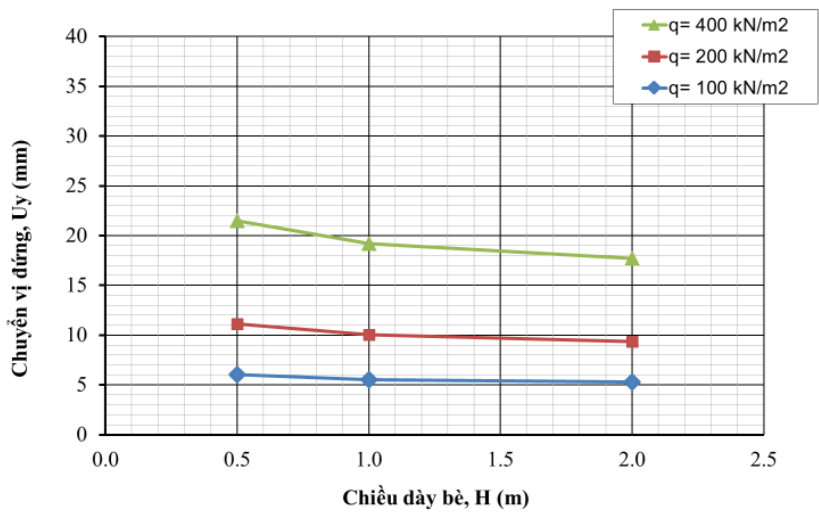

Hình 16. Ảnh hưởng của chiều dày bè đến chuyển vị theo phương đứng khi móng chịu tải trọng ngoài thay đồi, $\mathrm{L}=40 \mathrm{~m}$.

Theo một số quan điểm thiết kế móng cọc hiện nay, chưa xem xét đến sự làm việc của đất nền dưới đáy bè và xem tải trọng công trình là do cọc chịu $100 \%$. Tuy nhiên theo quan điểm móng bè cọc thì tải trọng công trình vừa phân phối lên bè và vừa phân phối lên cọc, trong bài nghiên cứu này phần móng bè tham gia chịu lực từ $6 \%$ đến $29 \%$ khi áp lực do tải trọng ngoài tăng từ 100 kPa đến 400 kPa.

\section{Kết luận}

Kết quả nghiên cứu theo quan điểm tải trọng công trình vừa phân phối lên bè và vừa phân phối lên cọc, khi chiều dài cọc $\mathrm{L}=30 \mathrm{~m}$ thì phần móng bè tham gia chịu lực từ $6 \%$ đến $29 \%$ khi áp lực do tải trọng ngoài tăng từ $100 \mathrm{kPa}$ đến $400 \mathrm{kPa}$, khi chiều dài cọc $\mathrm{L}=40 \mathrm{~m}$ thì phần móng bè tham gia chịu lực từ $6 \%$ đến $29 \%$ khi áp lực do tải trọng ngoài tăng từ $100 \mathrm{kPa}$ đến $400 \mathrm{kPa}$.

Chiều dày bè không ảnh hưởng nhiều đến chuyển vị trung bình, việc chuyển vị trung bình giảm khi tăng chiều dày bè là hậu quả của việc giảm chuyển vị lệch. Nhưng chiều dày bè lớn có thể giảm chuyển vị lệch rất mạnh mẽ, hỗ trợ cho các thiếu sót khi chọn sơ đồ bố trí cọc, lựa chọn cọc hoặc các nguyên nhân về đất nền. Khi chiều dài cọc $\mathrm{L}=30 \mathrm{~m}$, tăng chiều dày của bè tăng từ $0,5 \mathrm{~m}$ đến $2,0 \mathrm{~m}$ thì độ lún lệch giảm từ $37 \mathrm{~mm}$ đến 9 $\mathrm{mm}$. Khi chiều dài cọc $\mathrm{L}=40 \mathrm{~m}$, tăng chiều dày của bè tăng từ $0,5 \mathrm{~m}$ đến $2,0 \mathrm{~m}$ thì độ lún lệch giảm từ $21 \mathrm{~mm}$ đến $5 \mathrm{~mm}$. Trong nghiên cứu này độ lún lệch không đáng kể khi chiều dày bè bằng $2 \mathrm{~m}$.

\section{Tài liệu tham khảo}

[1]. Võ Phán. Các phương pháp khảo sát hiện trường và thí nghiệm đất trong phòng, Đại học Bách Khoa TP. Hồ Chí Minh, 220-226, 2012.

[2]. Châu Ngọc Ẩn. Nền móng, NXB Đại học Quốc gia TP. Hồ Chí Minh, 2012.

[3]. Phung Duc Long. Piled Raft - A Cost-Effective foundation method for highrises, Geotechnical Engineering Journal of the Seags \& Agssea Vol 41, No 3 September 2010 Issn 0046-5828.

[4]. Cao Văn Hóa. Phân tích ứng xử lún của bản móng trên hệ cọc bằng chương trình PRAB, Tuyển tập hội thảo "Địa kỹ thuật vì sự phát triển xanh", 2013. 